\title{
Synthesis and Biological Evaluation of New 3,4-diarylmaleimides as Enhancers (modulators) of Doxorubicin Cytotoxic Activity on Cultured Tumor Cells from a Real Case of Breast Cancer
}

\author{
Jessica R. Gutierrez-Cano, Pradip D. Nahide, ${ }^{1 \&}$ Velayudham Ramadoss, ${ }^{1 \&}$ Yuvraj Satkar, ${ }^{1}$ \\ Rafael Ortiz-Alvarado, ${ }^{3}$ Clara Alba-Betancourt, ${ }^{2 *}$ Claudia L. Mendoza-Macías, ${ }^{2 *}$ and \\ César R. Solorio-Alvarado ${ }^{1 *}$ \\ 1 Departamento de Química, División de Ciencias Naturales y Exactas, Campus Guanajuato, Universidad de Guanajuato. \\ Cerro de la Venada S/N, 36040, Guanajuato, Gto., México. \\ 2 Departamento de Farmacia, División de Ciencias Naturales y Exactas, Campus Guanajuato, Universidad de Guanajuato. \\ Noria Alta S/N, 36050, Guanajuato, Gto., México. \\ 3 Facultad de Químico Farmacobiología, Universidad Michoacana de San Nicolás de Hidalgo, Tzintzuntzan 173, \\ Colonia Matamoros, 58240, Morelia, Michoacán, México. \\ \& These authors contribute equally to the paper. \\ *Correspondence: csolorio@ugto.mx; c.albabetancourt@ugto.mx; cl.mendoza@ugto.mx
}

Received August 1st, 2016; Accepted January 11th, 2017.

\begin{abstract}
A series of new 3,4-diarylmaleimides were synthesized in an optimized and efficient lineal sequence of three steps, starting from commercial maleimide. The biological evaluation of these compounds as enhancers (activity modulators) in the co-administration with doxorubicin treatment in breast cancer cells directly obtained from a patient, were essayed. The cancerous tissue BT026-512N was provided by the National Institute of Cancerology (INCAN) of México. This tissue was obtained by biopsy from a patient diagnosed with stage IIB ductal breast cancer. The results obtained in the assays, show decreased cell viability on the cultured cells for all of the maleimides synthesized in combinatorial administration with doxorubicin. The highest mortality effect was determined for maleimides 9 and 29 increased in close to three times the effect compared with treatment using only doxorubicin. Based on previous functionalized maleimides core reports and Molinspiration chemoinformatic analysis, these results could possibly point out to the Pg-p glycoprotein as bio-molecular action target of maleimides by kinase phosphorylation-inhibition, although more experimental data is necessary.
\end{abstract}

Keywords: Breast cancer, Maleimide; Doxorubicin; synergistic cancer treatment.

\section{Introduction}

Breast carcinoma is the most prevalent invasive malignancy among women worldwide, and constitutes one-third of all cancers and is the second cause of mortality only after lung cancer. Of all histological types of breast carcinomas, invasive ductal carcinoma (IDC), is the most prevalent type with an incidence of about $83 \%$. [1] Anthracyclines are among the most effective and commonly used chemotherapeutic drugs [2] and are the
Resumen: Una serie de nuevas 3,4-diarilmaleimidas fueron sintetizadas en una secuencia lineal optimizada y eficiente de tres pasos, iniciando de maleimida comercial. La evaluación biológica de estos compuestos como potenciadores (moduladores de actividad) en la coadministración con el tratamiento de doxorrubicina en un caso de células obtenidas de un paciente con cáncer de mama, fueron ensayados. El tejido canceroso BT026-512N fue provisto por el Instituto Nacional de Cancerología (INCAN) de México. Este tejido fue obtenido por biopsia de un paciente diagnosticado con cáncer de mama izquierdo con infiltración ductal en etapa IIB. Los resultados obtenidos en los ensayos muestran de manera general incremento en la mortalidad celular de los cultivos para todas las maleimidas sintetizadas en administración combinatoria con doxorrubicina. El efecto de mortalidad más alto fue determinado para las maleimidas 9 y 29 incrementando cerca de tres veces el efecto comparado con el tratamiento utilizando solamente doxorrubicina. Con base a reportes previos del núcleo funcional de las maleimidas así como un análisis quimioinformático en Molinspiration, estos resultados pudieran sugerir a la glicoproteína Pg-p como blanco biomolecular de acción de las maleimidas por la inhibición de la fosforilación de la cinasa, aunque más experimentos son necesarios para corroborarlos.

Palabras Clave: Cáncer de mama; maleimida; doxorrubicina; tratamiento sinérgico para cáncer.

most effective classes of cytotoxic agents for early stage breast cancer.

Anthracyclines are able to diffuse across the cell membrane, intercalate between DNA base pairs, generate free radicals (thus damaging DNA), target topoisomerase II (TOPOII), and induce cell apoptosis. [3]

The first generation of anthracyclines such as doxorubicin (Dox) and daunorubicin (Dnr), were isolated from Streptomyces peucetius, and display good activity against murine tumors 
[4-5]. Dox is an antibiotic with broad spectrum of antitumor activity in a variety of solid tumors including neuroblastoma, leukemia, Hodgkin's lymphoma, bladder and breast cancers, among others. However, it has a limited therapeutic index due to toxic side effects such as cardiotoxicity and high incidence of multiple drug resistance (MDR). [6-7]

The MDR mechanisms of anthracyclines are complicated and not fully understood. The most established mechanism of resistance is the over-expression of drug efflux proteins, particularly members of the ATP-binding cassette (ABC) superfamily: P-glycoprotein (P-gp), multidrug resistance protein 1 (MRP1), and breast cancer resistance protein (BCRP). Anthracyclines are known to be efficient substrates for $\mathrm{ABC}$ transporters. For example, P-gp, a membrane transporter encoded by MDR1 gene, pumps out a variety of hydrophobic anticancer drugs out of the cell, resulting in a decreased intracellular drug accumulation. [8-9] Therefore, the task of maintaining doxorubicin inside the tumor site, with high efficacy combined with low systemic exposure is a major challenge. Verapamil, a calcium channel blocker, was the first MDR reversal agent that was found to inhibit P-gp-mediated drug efflux. [10] Several compounds, containing a common 3,4-diaryl-substituted pyrrole nucleus bearing 2- or 2,5-carboxylates, can reverse MDR more effectively than verapamil by inhibiting the P-gp-mediated drug efflux at a noncytotoxic concentration. [11] Thus, in this work, new 3,4-diaryl maleimides were synthetized in order to improve doxorubicin cytotoxic activity, by modifying its substituents using the Suzuki-Miyaura cross-coupling reaction. These novel compounds and doxorubicin were assessed for their synergistic cytotoxic activity on cancer cells obtained from a breast cancer patient.

\section{Results}

\section{Organic Synthesis}

The synthesis of compounds 5-24 (table 2) was carried out by using Suzuki cross-coupling reaction among three
$\mathrm{N}$-alkyl-substituted 3,4-dibromomaleimide derivatives 2-4 and different aryl boronic acids. Thereby the synthetic protocol was developed in two lineal stages: 1) Synthesis of $N$-alkyl-3,4-dibromomaleimides and 2) The Suzuki cross-coupling to obtain the different drugs. The first stage is outlined in Scheme 1. Mild bromination of commercially available maleimide yields compound 1 in $92 \%$. The consecutive $N$-alkylation of 1 with $\mathrm{Me}_{2} \mathrm{SO}_{4}$, benzyl bromide and 3,4-dimethoxyphenethylbromide yield 2-4 respectively.

It is important to mention that compound $\mathbf{4}$ was obtained in very low yield, just enough for chemical characterization and it was not used in subsequent reactions.

The second stage consists on the Suzuki cross-coupling reaction. In order to get optimal yields for the different molecules to be synthesized, the organometallic procedure was optimized using $\mathbf{2}$ and phenylboronic acid as model system (Table 1).

Different palladium catalyst sources $\left(\mathrm{Pd}^{0}\right.$ and $\left.\mathrm{Pd}^{\mathrm{II}}\right)$ were tested in catalytic amount corresponding to 2, 4, 6 and $8 \mathrm{~mol} \%$. The reaction was carried out at room temperature and $90{ }^{\circ} \mathrm{C}$. On the other hand, sodium carbonate, cesium carbonate and tribasic potassium phosphate were tested as the bases. Also 1,4-dioxane, tetrahydrofuran (THF) and toluene:ethanol $(\mathrm{PhMe}: \mathrm{EtOH})(3: 1)$ were the solvents explored. Finally, the reactions were monitored from 3 to $24 \mathrm{~h}$ and the corresponding yields were determined by ${ }^{1} \mathrm{H}$ NMR spectroscopy using anisole as internal standard. In the first set of reactions, $\mathrm{Pd}\left(\mathrm{PPh}_{3}\right)_{4}$ and sodium bicarbonate in PhMe:EtOH (3:1) were tested during 3.5 to $6.5 \mathrm{~h}$ (entries 1-6). For this set of reactions, the use of $2 \mathrm{~mol} \%$ gives better yield at $90{ }^{\circ} \mathrm{C}$ than room temperature. Thus, $2 \%$ and $84 \%$ of yield were obtained (entries 1 and 4 ). The best yield of this set was obtained using $4 \mathrm{~mol} \%$ of catalyst at $90{ }^{\circ} \mathrm{C}(88 \%$, entry 5) while increasing the catalytic charge decreased the yield to $10 \%$ and $60 \%$ respectively (entries 3 and 6). Under the previously set assayed conditions taking $\mathrm{Pd}\left(\mathrm{PPh}_{3}\right)_{2} \mathrm{Cl}_{2}$ instead of palladium tetrakis, the yields decreased (entries 7-12). For the next group of reactions (entries 13-16) tribasic potassium phosphate and 1,4-dioxane was used keeping $\mathrm{Pd}\left(\mathrm{PPh}_{3}\right)_{2} \mathrm{Cl}_{2}$ as palladium catalyst in 4 and $8 \mathrm{~mol} \%$. The reactions at room

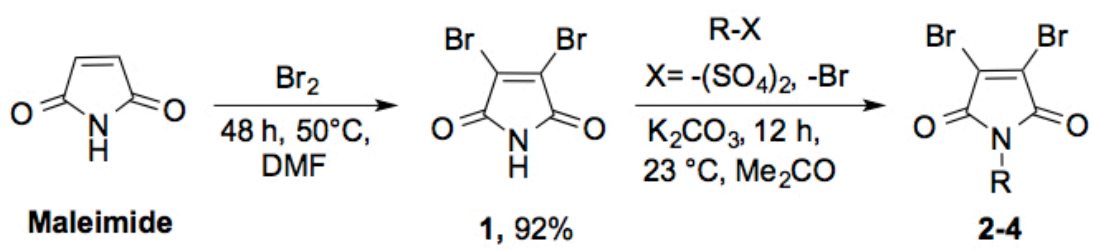

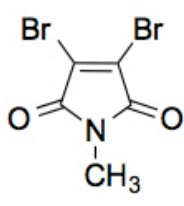

2, $75 \%$

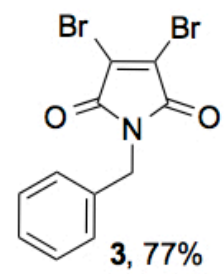

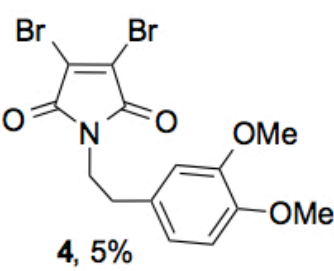

Scheme 1. Synthesis of the $N$-alkyl-substituted 3,4-dibromomaleimides 2-4. 
Table 1. Suzuki cross-coupling reaction optimization in the synthesis of 3,4-diphenyl- $N$-methylmaleimides.<smiles>CN1C(=O)C(Br)=C(Br)C1=O</smiles>

2<smiles>OB(O)c1ccccc1</smiles>
$\mathrm{Pd}^{(0)}$ or $\mathrm{Pd}^{(\mathrm{II})}$<smiles>CN1C(=O)C(c2ccccc2)=C(c2ccccc2)C1=O</smiles>

5

\begin{tabular}{|c|c|c|c|c|c|c|c|}
\hline Entry & $\mathrm{Pd}$ & $\mathrm{mol} \%$ & $\begin{array}{c}\text { Temperature } \\
\left({ }^{\circ} \mathrm{C}\right)\end{array}$ & Base & Solvent & $\begin{array}{l}\text { Time } \\
\text { (h) }\end{array}$ & $\begin{array}{c}\text { Yield }^{a} \\
(\%)\end{array}$ \\
\hline 1 & \multirow[t]{3}{*}{$\mathrm{Pd}\left(\mathrm{PPh}_{3}\right)_{4}$} & 2 & 23 & \multirow[t]{3}{*}{$\mathrm{Na}_{2} \mathrm{CO}_{3}$} & \multirow[t]{3}{*}{ PhMe:EtOH } & 6.5 & 2 \\
\hline 3 & & 8 & 23 & & & 6.5 & 10 \\
\hline 4 & & 2 & 90 & & & 3.5 & 84 \\
\hline 7 & \multirow[t]{4}{*}{$\mathrm{Pd}\left(\mathrm{PPh}_{3}\right)_{2} \mathrm{Cl}_{2}$} & 2 & 23 & \multirow[t]{4}{*}{$\mathrm{Na}_{2} \mathrm{CO}_{3}$} & \multirow[t]{4}{*}{ PhMe:EtOH } & 6 & 54 \\
\hline 8 & & 4 & 23 & & & 6 & 86 \\
\hline 9 & & 8 & 23 & & & 6 & 28 \\
\hline 10 & & 2 & 90 & & & 3 & 61 \\
\hline 14 & \multirow{3}{*}{$\mathrm{Pd}\left(\mathrm{PPh}_{3}\right)_{2} \mathrm{Cl}_{2}$} & 8 & 23 & \multirow{3}{*}{$\mathrm{K}_{3} \mathrm{PO}_{4}$} & \multirow{3}{*}{ 1,4-dioxano } & 24 & 33 \\
\hline 15 & & 4 & 90 & & & 3.5 & 88 \\
\hline 16 & & 8 & 90 & & & 3 & 65 \\
\hline 17 & \multirow[t]{4}{*}{$\mathrm{Pd}\left(\mathrm{PPh}_{3}\right)_{2} \mathrm{Cl}_{2}$} & 4 & 23 & \multirow[t]{4}{*}{$\mathrm{Cs}_{2} \mathrm{CO}_{3}$} & \multirow[t]{4}{*}{ THF } & 20 & 44 \\
\hline 18 & & 8 & 23 & & & 20 & 41 \\
\hline 19 & & 4 & 90 & & & 3 & 48 \\
\hline 20 & & 8 & 90 & & & 3 & 18 \\
\hline
\end{tabular}

${ }^{a}$ Chemical yields were determined by ${ }^{1} \mathrm{H}$ NMR using anisole as internal standard.

temperature gave low yields ( $21 \%$ and $33 \%$ respectively, entries 13 and 14). On the other hand, by increasing the temperature to $90^{\circ} \mathrm{C}$ we found the best results for our optimization. The reaction proceeded in only $3.5 \mathrm{~h}$ ( $88 \%$, entry 15$)$. Additional experiments increasing the catalytic charge (entry 16) or changing solvent and base, resulted in low to modest chemical yields $18-44 \%$ (entries 17-20). From our optimization we conclude that conditions in entries 5 and 15 were the best. However reagents in entry 15 were chosen mainly by the lower cost of palladium catalyst.

With the Suzuki cross-coupling reaction optimized conditions in hand, we synthesized a pool of 3,4-diarylmaleimides substituted at nitrogen with methyl and benzyl group (Table 2).

Thus a wide variety of boronic acids from commercial sources were acquired. We considered those containing electron-donating, electron-attracting, electron-neutral as well as heterocyclic and polyaromatic groups. It is relevant to highlight that some groups like fluorine and chlorine have displayed important biological activities, as consequence were included in the substitution pattern of the prepared molecules in this work.

As we can see, several 3,4-diaryl- $N$-alkylmaleimides were synthesized in modest to excellent yields. As planned, maleimides containing electron-rich (entries 2-3, 6-7, 12-13 and 1516), electron-poor (entries 4-5, 8-10, 14 and 17-19) and neutral aryls (entries 1 and 11) were prepared.

On the other hand, some related 3-bromo-4-aminomaleimides structurally related were synthesized using $\mathbf{1}$, as starting material (Scheme 2).

The compounds 25-27 were conveniently prepared by mixing compound 1 with benzylamine, phenethylamine and 3,4-dimethoxyphenetyl amine respectively. The reaction takes place in two consecutive steps: the first one corresponding to the transamidation intermediates $\mathbf{2 5 a - 2 7 a}$, followed by bromine substitution via a Michael addition-elimination. 
Table 2. Synthesis of 3,4-diaryl- $N$-alkylmaleimides by Suzuki cross-coupling reaction.<smiles>[R]N1C(=O)C(Br)=C(Br)C1=O</smiles><smiles>[R18][R](O)O</smiles>

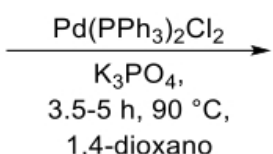

1,4-dioxano<smiles>[R]C1=C([R])C(=O)N([R])C1=O</smiles>

$5-24$

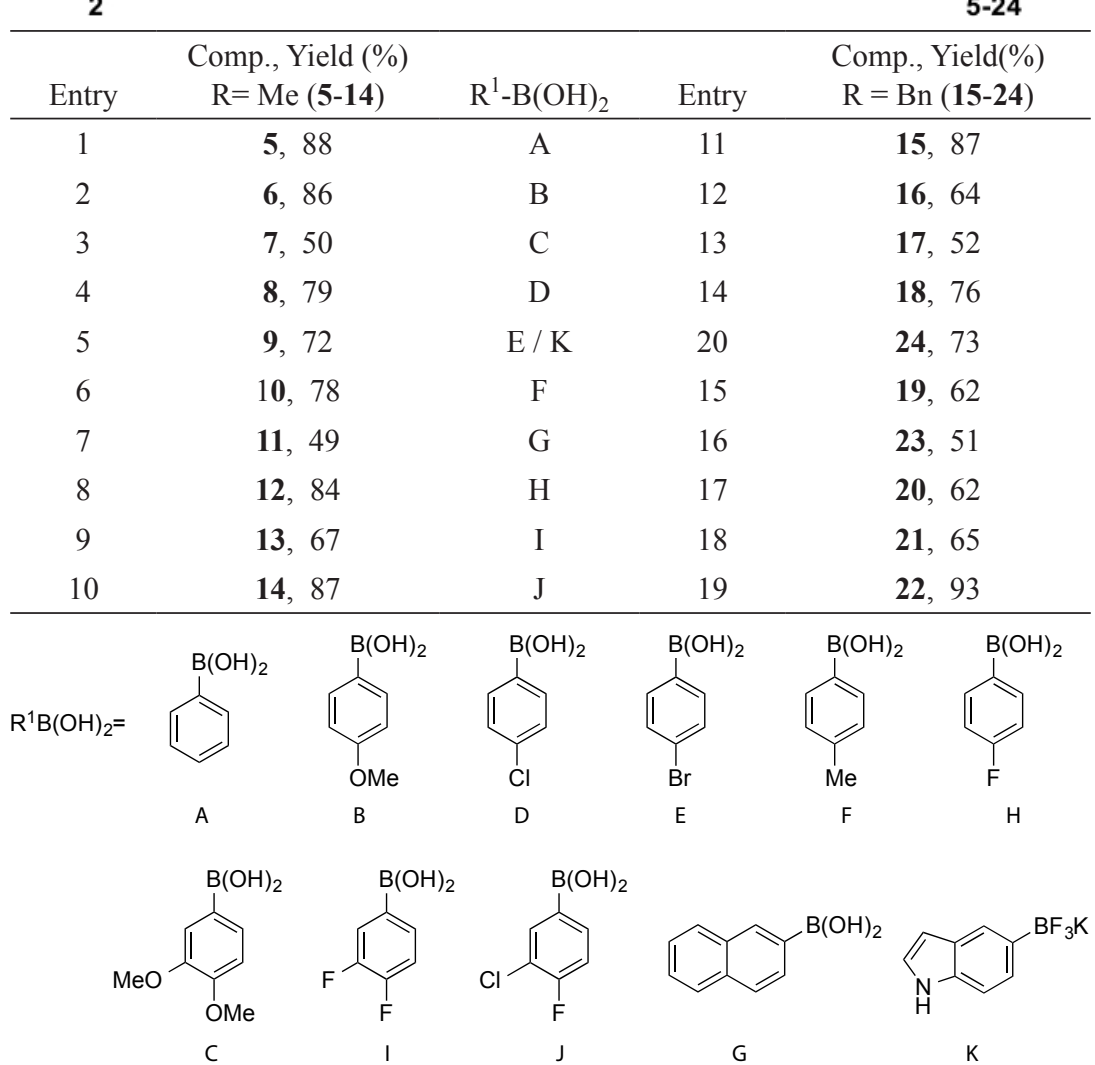
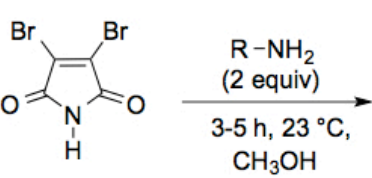

$\mathrm{CH}_{3} \mathrm{OH}$

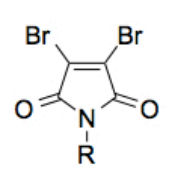

25a-27a

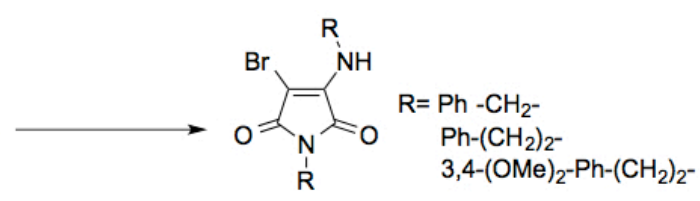

25-27<smiles>O=C1C(Br)C(NCc2ccccc2)C(=O)N1Cc1ccccc1</smiles>

$25,58 \%$

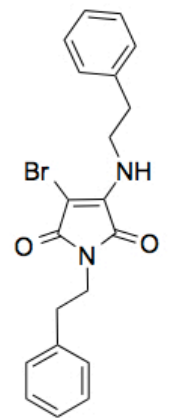

26, $96 \%$

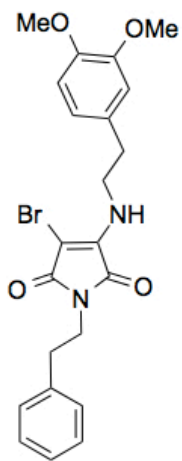

27, $65 \%$

Scheme 2. Synthesis of 3-bromo-4-aminomaleimides 25-27. 


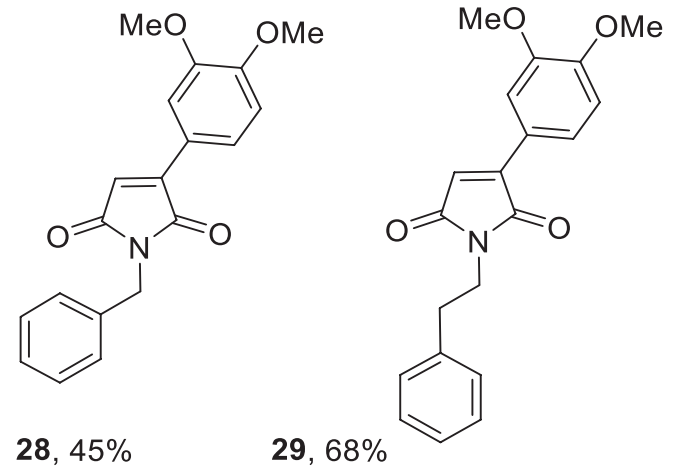

Figure 1. Additional $C$-monoarylmaleimides 28-29 tested.

Finally, compounds 28-29 (monsubstituted maleimides) were synthesized according to the procedure described in Figure 1.

\section{Drug screening \\ BT 026-512N breast cancer cells from primary culture}

BT 026-512N breast cancer cells, obtained from a patient biopsy, who was diagnosed with (left) stage IIB infiltrating ductal breast cancer, were stabilized in primary cell cultures. As shown in Figure 2, these cells were immunoreactive to cytokeratin 19, a breast cancer marker. [12] The synergistic cytotoxic effect exerted by doxorubicin and 3,4-diarylmaleimides derivatives (529) were tested on these primary cell cultures.

\section{Synergistic effect of doxorubicin and 3,4-diarylmaleimides derivatives}

In the present study, the series of 25 3,4-diarylmaleimides derivatives (5-29) synthesized were tested in combination with doxorubicin in BT 026-512N cells from secondary culture. Breast cancer cell cytotoxicity to Dox alone or in combination with 3,4-diarylmaleimides derivatives (5-29) was evaluated by determining the cell proliferation inhibition as a percentage after $72 \mathrm{~h}$ of treatment with concentration range of 2-49 $\mathrm{mM}$ of each derivative as shown in Table 3. Combination of 3,4-diarylmaleimides derivatives $\mathbf{9}, \mathbf{1 6}, \mathbf{2 0}$ and $\mathbf{2 9}$ at concentrations 2.4, 12.5, 26.6 and $8.9 \mathrm{mM}$ respectively with $0.4 \mathrm{mM}$ of Dox showed the best degree of cell proliferation inhibition above two-fold change compared with the cell proliferation inhibition of Dox alone (25.6\%, Figure 3).

Secondary cultures of BT $026-512 \mathrm{~N}$ cells maintained reactivity to cytokeratin 19 antibody showing a stable phenotype as breast cancer cells after subculture for 3,4-diarylmaleimides derivatives testing (data not shown).

\section{Predicted physicochemical and biological activities of 3,4-diarylmaleimides derivatives}

Molinspiration property engine v2014.11, were used to calculate the physicochemical and bioactive theoretical properties of 3,4-diarylmaleimides derivatives, which exerted the highest synergistic cytotoxic effect with Dox. Molinspiration offers a molecular processing and property calculation toolkit written in Java. The toolkit may be used in a batch to process large number of molecules (processing speed is about 10,000 molecules/ minute), or accessed through web interface directly on your intranet. Calculated molecular descriptors may be used for property based virtual screening of large collections of molecules to discard structures without drug-like properties and to pick potential drug candidates. These calculations were performed along with the experimental procedure. Through molecular descriptors such as $\log$ P, Molecular weight, number of Hydrogen donators and acceptors at the molecule, used as the "rule of five", described by Lipinski in 1997, [13] is able to predict drug-likeness in new molecules. The rule states, that most "drug-like" molecules have log P less than 5, molecular weight less than 500, number of hydrogen bond acceptors less than 10, and number of hydrogen bond donors less than 5. Molecules

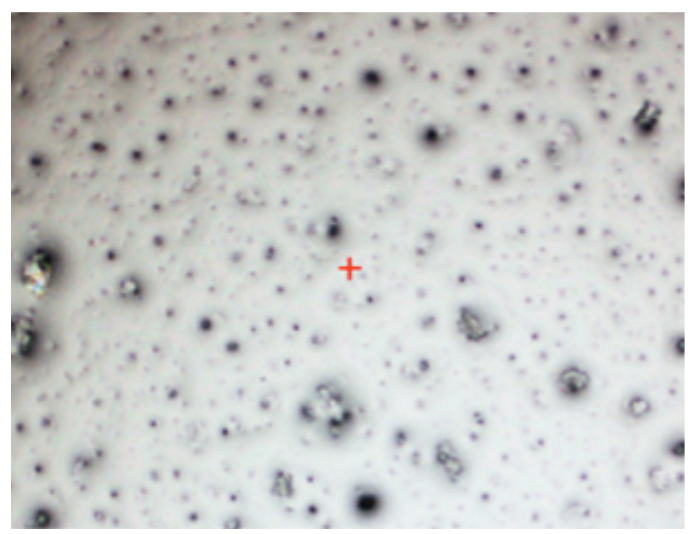

(a)

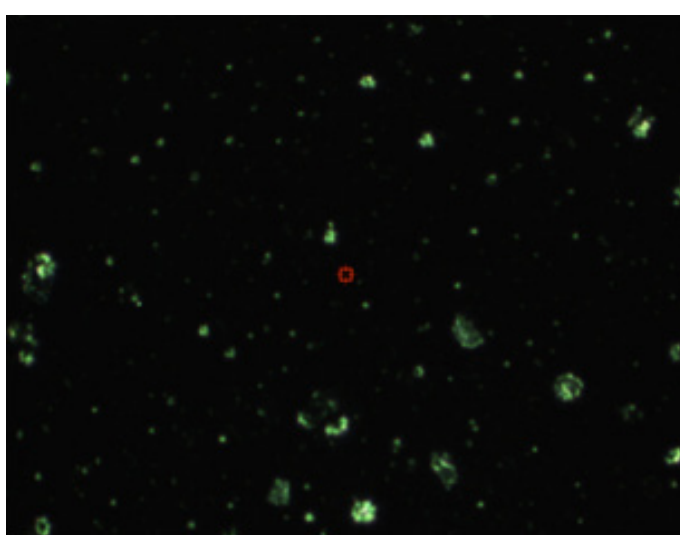

(b)

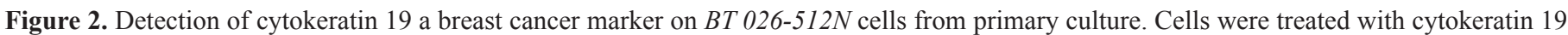

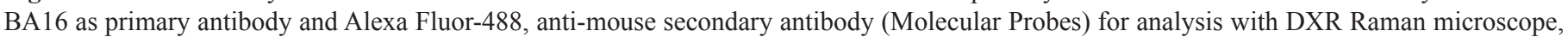

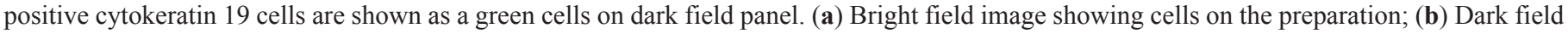
image showing green fluorescent cells positive for cytokeratin 19 . 

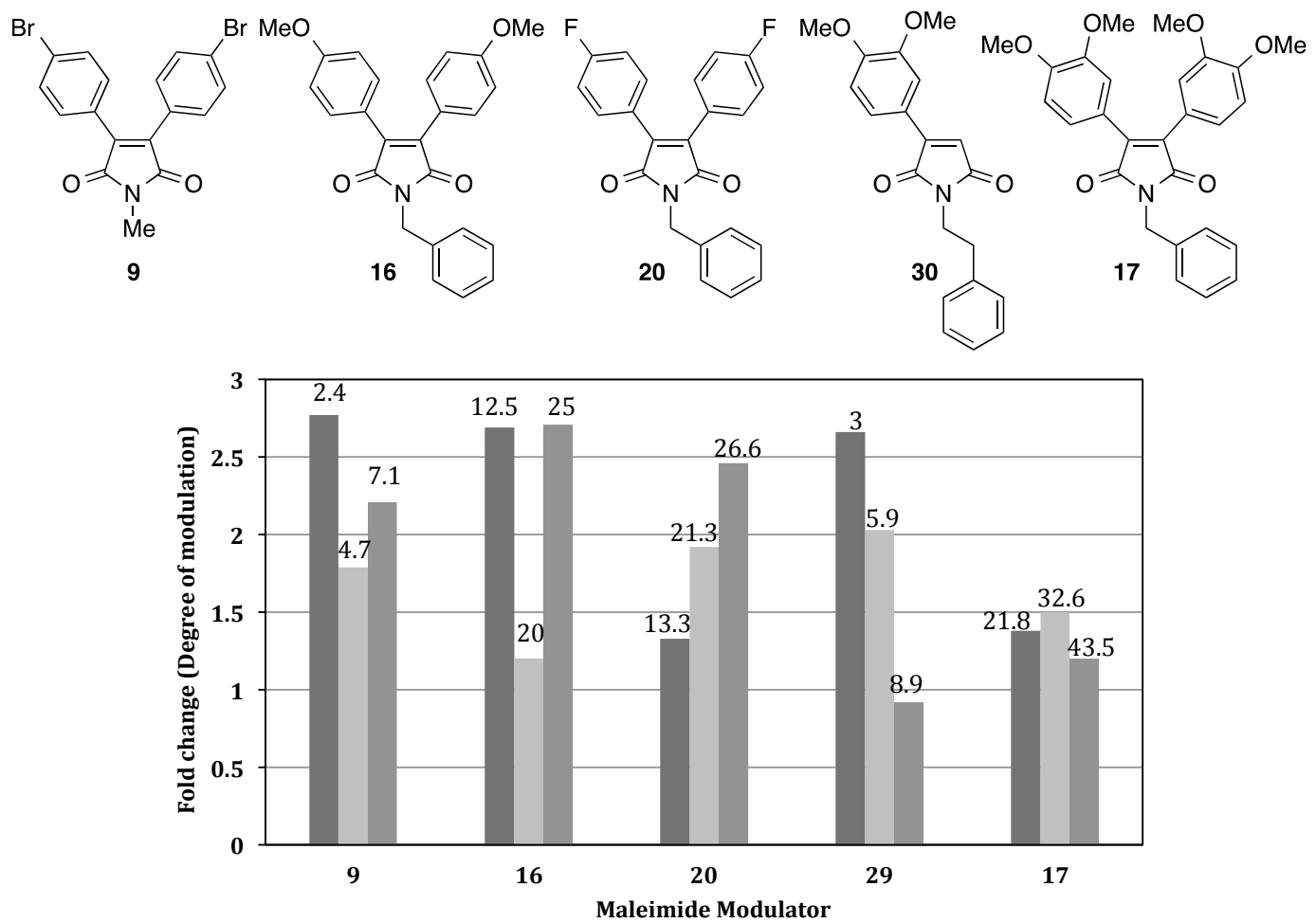

Figure 3. Structure and degree of modulation of 3,4-diarylmaleimides derivatives on Dox cytotoxicity activity. Four maleimide derivatives 9, 16, $\mathbf{2 0}$ and $\mathbf{2 9}$ at three diferent concentrations (values on top of bars, $\mathrm{mM}$ ) and a previously reported compound $\mathbf{1 7}$ were tested in combination with Dox $(0.4 \mathrm{mM})$. Fold change in cytotoxicity effect versus Dox alone was calculated. Structure of tested derivatives are shown above the graphic.

violating more than one of these rules may have problems with bioavailability. In Table 3 the physicochemical properties and drug-likeness of 3,4-diaryl-maleimides are shown.

\section{Discussion}

The screening essays were started by determining cell proliferation inhibition using doxorubicin only (table 3 , entry 1 ). A $25.6 \%$ of cell proliferation inhibition was obtained; this value was used as reference to calculate the relative fold (RF), which is defined as the ratio between cell proliferation inhibition with and without enhancer. Afterwards, compounds 5-29 were tested in combination with a fixed Dox concentration = $0.4 \mathrm{mM}$ and 72 hours of incubation. Moreover, as previously described, compound $\mathbf{1 7}$ was used as reference [11]. Compound 17 is a Ningalin B analogue, obtained by Zhang et al., by linking 3,4-diaryl-substituted pyrrole-2,5-dione with a benzene ring (D-ring) containing various alkyl linkers. Ningalin B is a member of a newly described family of marine natural products which have been reported to act as nontoxic inhibitors of MDR in various cancer cell lines. [11] Compound $\mathbf{1 7}$ at a very high concentration $(100 \mu \mathrm{M})$, did not show any cytotoxicity toward the breast cancer cell lines used nor to normal mouse connective tissue fibroblast. It contains one methylene linker to the D-ring, and it displayed about 2-fold higher enhancer paclitaxel cytotoxic activity than compounds with bismethylene, suggesting that shorter linker in permethyl ningalin B analogues is crucial for modulating Pgp. [11].

Obtained results reveal the expected enhancement of Dox activity for every synthesized maleimide resulting in increasing cell proliferation inhibition. Remarkably by using maleimide modulators 9, 16, 20 and 29 cell proliferation inhibition increases by 2 -fold or more (Table 3 ).

Three different combinatorial concentrations of maleimides were tested. The reference compound $\mathbf{1 7}$ shows a moderate $\mathrm{RF}=1.50$ at $32.6 \mathrm{mM}$ (Table 3, entry 15 ). $N$-methylmaleimide 9 (Table 3, entries 2-4), containing electron-poor bromine group, results in the best biological activity regarding a good $\mathrm{RF}=2.77$ and a lower concentration $(2.4 \mathrm{mM})$. Other concentrations 4.7 and $7.1 \mathrm{mM}$ resulted in a lower RF. On the other hand, monosubstituted electron rich $\mathrm{N}$-benzyl-3,4-dimethoxyphenyl maleimide 29 (Table 3, entries 11-13) shows a comparable but slightly lower good activity with $\mathrm{RF}=2.66$ at $3 \mathrm{mM}$ concentration. For this compound a consistent decreased activity was observed by increasing the modulator concentration. Modulator 16 (Table 3, entries 5-7), shows a good RF=2.69 but in 12.5 and $25 \mathrm{mM}$. Finally, the fluorinated maleimide modulator 20 (Table 3, entries 8-10), gives the highest activity at a 26.6 $\mathrm{mM}$ concentration observing a consistent fold increasing while concentration does.

Drug-like properties may be expressed as the concise balance of several molecular properties and structural features, which determine if a particular molecule is similar to lead 
Table 3. Cell proliferation inhibition values of treatments with doxorubicin and 3,4-diaryl Maleimides derivatives and the respective Fold change.

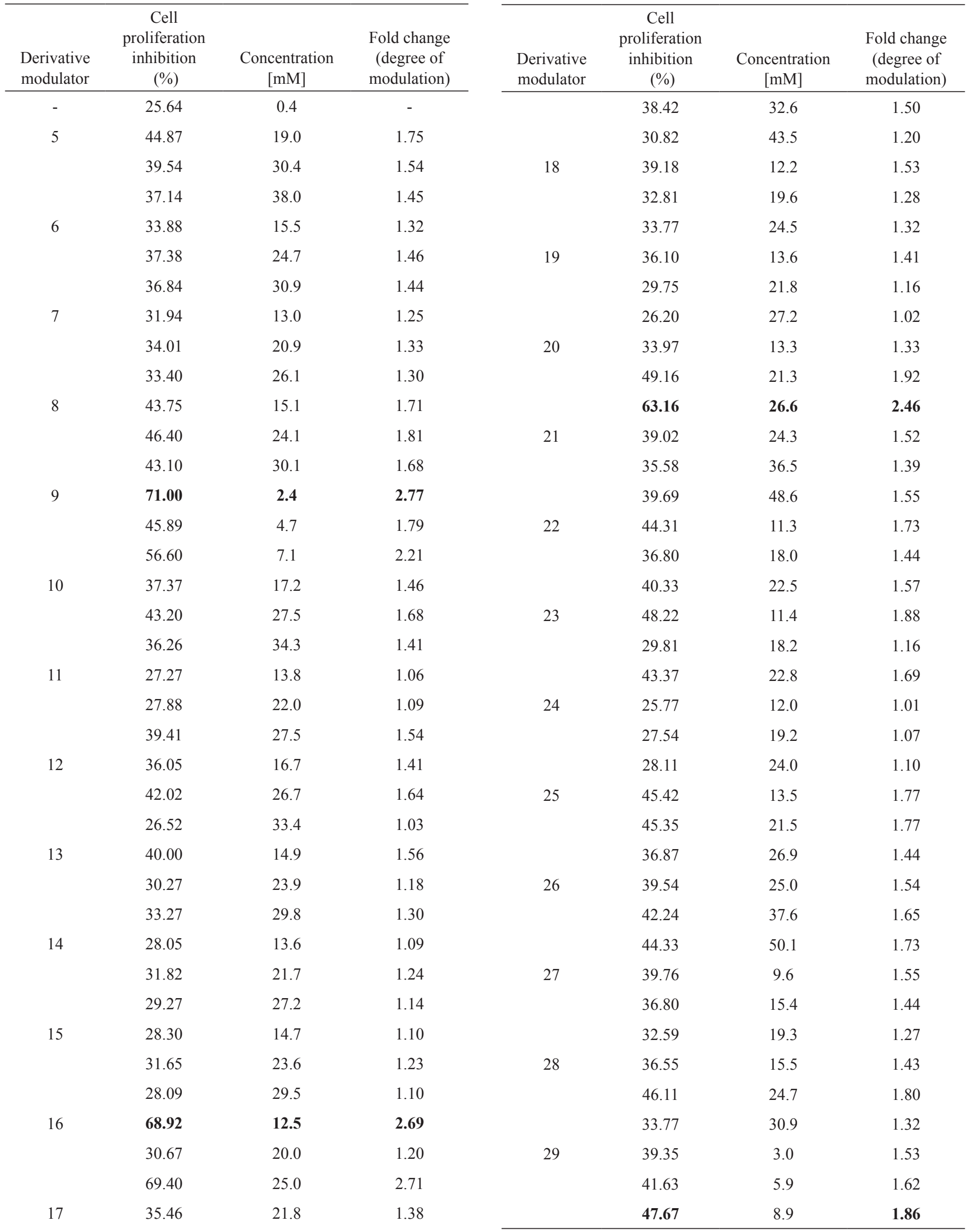


Table 4. Molinspiration analysis of theoretical physicochemical and bioactive properties of $N$-alkylmaleimide derivatives.

\begin{tabular}{|c|c|c|c|c|c|c|c|c|c|}
\hline \multirow[b]{2}{*}{ Comp } & \multirow{2}{*}{$\begin{array}{c}\text { MW } \\
\text { (g/mol) }\end{array}$} & \multicolumn{4}{|c|}{ Physicochemical properties } & \multirow[b]{2}{*}{ Nviol } & \multicolumn{3}{|c|}{ Drug-likeness score } \\
\hline & & $\mathbf{O}+\mathbf{N}$ & $\mathrm{OH}+\mathrm{NH}$ & cLog $P$ & TPSA & & KI & NRL & EI \\
\hline 9 & 421 & 3 & 0 & 4,85 & 39 & 0 & 0,25 & $-0,01$ & $-0,2$ \\
\hline 20 & 375 & 3 & 0 & 5,16 & 39 & 1 & 0,24 & 0,13 & 0,12 \\
\hline 29 & 323 & 5 & 0 & 2,75 & 57 & 0 & 0,33 & 0,03 & 0,06 \\
\hline
\end{tabular}

$M W$ Molecular Weight; $O+N$ number of hydrogen bond acceptors; $O H+N H$ number of hydrogen bond donors; cLog $P$ calculated log P value; TPSA Total Polar Surface Area; Nviol number of violation; KI kinase inhibitor; NRL Nuclear receptor ligand; EI enzyme inhibitor.

drugs. These properties, mainly hydrophobicity, electronic distribution, hydrogen bonding, molecular size, flexibility and the presence of some pharmacophoric influence parameters of a given molecule like bioavailability, distribution, plasma protein binding, bioactivity prediction, toxicity, and metabolic stability. Molinspiration is a chemoinformatic software that can estimate all of the above properties. [15]

Molinspiration software calculations were carried out for the molecules shown in Table 4. Mainly the hydrophilicity or hydrophobicity (cLog P) and Molecular Polar Surface Area (TPSA) parameters were analyzed to estimate the bioavailability of drug molecules. The compounds 9, 16, 29 and 17 show values below 5 , which imply a good membrane penetration accordant to the rule of Lipinski. [13] Compound 20 with slightly higher $\operatorname{cLog} \mathrm{P}=5.16$ will show less water affinity by overpassing the highest limit of 5 for this parameter, incurring in the only violation for the rule of five in this series of molecules. Regarding the TPSA for these five molecules is important to highlight that a value no bigger than $76 \AA^{2}$ was calculated. The value is important by the fact that according to the rule of five, when a drug presents a number higher than $140 \AA^{2}$ a poor intestinal absorption is expected. The compounds 9, 16, 20, 29 and 17 show all of them minor values for this TPSA descriptor. The aforementioned means that a good drug absorption including intestinal absorption, blood-brain barrier penetration as well as bioavailability may be favorable.

Bioactivity prediction by Molinspiration analysis of chemical structures showed the highest scores for kinase inhibitors in the compounds 9, 16, 20, 29 and 17. Molinspiration miscreen engine allows fast prediction of biological activity - virtual screening of large collections of molecules and selection of molecules with the highest probability to show biological activity. The screening is based on identification of fragments or substructure features typical for the active molecules. No information about the 3D structure of receptor is necessary, the set of active molecules (encoded as SMILES or SDfile) is sufficient for training, therefore the procedure may be applied also in the early project stage when detailed information about the binding mode is not yet available. [15]

The predicted activity of the synthetized molecules suggested that the modulation of doxorubicin effect may be mediated through P-gp as previously reported for compound 17. [11,
14] P-gp phosphorylation has been reported as a mechanism of regulation of drug efflux [17], particularly in sensitive and resistant MCF-7 cell lines, an inhibition of a protein kinase $\mathrm{C} \alpha$ $(\mathrm{PKC} \alpha)$ showed an increase of intracellular Dox [16]. This data suggests that drugs $9,16,20,29$ and 17 , could act as potential inhibitors of a kinase and improve the anticancer effect exerted by Dox through modulation of P-gp activity. Experimental evidence is necessary in order to demonstrate its participation as modulator of P-gp activity and its kinase target as predicted in the Molinspiration analysis.

The rule of five is a set of defined parameters, to predict if a chemical compound has a promising or viable pharmacological or biological activity as drug in oral administration. These parameters are 1) The molecule should not contain more than 5 hydrogen bond donors, 2) No more than 10 hydrogen bond acceptors, 3) The molecular weight should be lower than 500, 4) The value for cLog P should not be higher than five. The parameters in the rule of five were fully covered for the set of our synthesized maleimides excluding to $\mathbf{2 0}$ with only 1 violation in cLog P. Remarkably compounds 9, 16, 20 and 29 show the highest activity in the series of 3,4-diarylmaleimides synthesized.

Compound 9 contains bromine in its structure, which could suggest this bulky element is necessary to block P-gp pump and allow an increased intracellular concentration of Dox. Compound 20 contains instead of bromine, fluorine which potentially interacts in less effective way with P-gp pump, due to its minor atomic size. This is reflected by its slightly lower degree of modulation on Dox cytotoxicity activity compared with compound 9.

As previously reported for Ningalin B analogues [11, 14], partial or full methylation of phenol rings might significantly improve P-gp-modulating activity, this structural characteristic is shared by compounds $\mathbf{1 6}$ and $\mathbf{2 9}$ and the reference compound 17. In addition, the results obtained with Molinspiration analysis that predict biological activity of these compounds, suggest that methylation of phenol rings allows interaction with P-gp pump. On the other hand, compound $\mathbf{1 6}$ and $\mathbf{2 9}$ improved the modulation effect on Dox cytotoxicity activity compared with reference compound $\mathbf{1 7}$, however in this work, our compounds showed higher activity with less methylated phenolic groups compared with compound 17. 


\section{Conclusions}

In summary for this primary breast cancer cell culture the 3,4-bisarylmaleimide core is a promising structure in a potential combination treatment with doxorubicin. The electron-deficient group in a 3,4-diarylmaleimide is a key structural factor. In addition, bigger substituents in both aryl and nitrogen in maleimide core, such as bromine and benzyl, increase the activity. Both characteristics in the same molecule not improved the cytotoxic effect according to this observation. On the other side $\mathrm{N}$-alkyl or benzyl substituted maleimides containing electron-donating groups at the aryl ring show also excellent activity. Those electron-rich and monoarylated maleimides will be in this sense the better combination. So big electron-poor and small at nitrogen or electron-rich monoarylated with big alkyl group at nitrogen is the other good possible combination.

\section{Supplementary Materials}

A copy of ${ }^{1} \mathrm{H}$ and ${ }^{13} \mathrm{C}$ NMR for compounds $\mathbf{1 - 2 9}$ as well as biological experimentation full data for all described maleimides are available online.

\section{Acknowledgments}

We gratefully thanks to FOMIX (CONACyT-CONCyTEG) GTO-2012-C03-194610 for financial support and fellowship for J.R. Gutiérrez-Cano. We acknowledge the facilities from the DCNE, Chemistry Department, Guanajuato University in the National Laboratory UG-CONACyT (LACAPFEM) for full characterization. We thanks to CONACyT for fellowships to V. Ramadoss, P.Nahide and Y. Satkar. We gratefully give thanks to the National Institute of Cancerology for providing tissue BT025-512N for biological essays. Also we thanks to Dr. $\mathrm{J}$. Gembe for providing doxorubicin sample.

\section{References}

1. Kamangar, F.; Dores, G.M.; Anderson, W.F. J. Clin. Oncol 2006, 24(14), 2137-2150. doi: 10.1200/JCO.2005.05.2308.
2. Binaschi, M.; Bigioni, M.; Cipollone, A.; Rossi, C.; Goso, C.; Maggi, C.A.; Capranico, G.; Animati, F. Anti-Cancer Agents 2001, 1(2), 113-130. DOI: 10.2174/1568011013354723.

3. Minotti, G.; Menna, P.; Salvatorelli, E.; Cairo, G.; Gianni, L. Anthracyclines. Pharmacol Rev 2004, 56(2), 185-229. doi: 10.1124/ pr.56.2.6.

4. Tan, C.; Tasaka, H.; Yu, K.P.; Murphy, M.L.; Karnofsk, D.A. Cancer 1967, 20(3), 333-353. DOI: 10.1002/1097-0142

5. Arcamone, F.; Cassinelli, G.; Fantini, G.; Grein, A.; Orezzi, P.; Pol, C.; Spalla, C. Biotechnol Bioeng 1969, 11(6), 1101-1110. DOI: 10.1002/bit.260110607.

6. Goldenberg, G.J.; Wang, H.; Blair, G.W. Cancer Res 1986, 46, 2978-2983. Available on line: http://cancerres.aacrjournals.org/ content/46/6/2978.long (accessed on 18 May 2016)

7. Rhinehart, J.J.; Lewis, R.P.; Balcerzak, S.P. Ann Intern Med 1974, 81, 475-478. doi:10.7326/0003-4819-88-2-168.

8. Lehne, G. Curr Drug Targets 2000, 1(1), 85-99. DOI: 10.2174/ 1389450003349443.

9. Kartner, N.; Riordan, J.R.; Ling, V. Science 1983, 221, 1285-1288. DOI: $10.1126 /$ science.6137059.

10. Tsuruo, T.; Iida, H.; Tsukagoshi, S.; Sakurai, Y. Cancer Res 1981, 41, 1967-1972. Available on line: http://cancerres.aacrjournals. org/content/41/5/1967.long (accessed on 19 May 2016).

11. Zhang, P.Y.; Wong, I.L.K.; Yan, C.S.W.; Zhang, X.Y.; Jiang, T.; Chow, L.M.C.; Wan, S.B. J Med Chem 2010, 53, 5108-5120. DOI: $10.1021 / \mathrm{jm} 100035 \mathrm{c}$.

12. Lacroix M. Endocr Relat Cancer. 2006, 13, 1033-1067. doi: 10.1677/ERC-06-0001.

13. Lipinski, C. A., Lombardo, F., Dominy, B. W.; Feeney, P. J. $A d v$ Drug Deliver Rev. 2001, 64, 3-26. doi:10.1016/S0169-409X (00)00129-0.

14. Bin, J. W., Wong, I. L., Hu, X., Yu, Z. X., Xing, L. F., Jiang, T., ... \& Biao, W. S. J Med Chem 2013, 56(22), 9057-9070. Doi: 10.1021/jm400930e.

15. Miscreen-Molinspiration Fragment-based Virtual Screening Engine written in Java; http://www.molinspiration.com/docu/miscreen/index.html. Accessed May 24, 2016.

16. Kim, C. W.; Asai, D.; Kang, J. H.; Kishimura, A.; Mori, T.; Katayama, Y. Tumor Biol. 2015, 37, 1901-1908. DOI 10.1007/s13277015-3963-4.

17. Meyers, M. B. Cancer Commun, 1989, 1(4), 233-241. 